\title{
A Clinical Study of Different Modalities for the Management of Chronic Maxillary Sinusitis
}

\author{
Sunil Sakinala ${ }^{1}$
}

\author{
Assistant Professor, Department of ENT, Prathima Institute of Medical Sciences, Naganoor, Karimnagar, \\ Telangana State.
} Corresponding Author: Dr. Sunil Sakinala, Assistant Professor, Department of ENT, Prathima Institute of
Medical Sciences, Naganoor, Karimnagar, Telangana State. Email:sunilsakinala@gmail.com

DOI:10.47799/pimr.0901.23

Receiving : 16/12/2020

Review: 24/12/2020

Acceptance :2/1/2021

\begin{abstract}
Background: Chronic maxillary sinusitis is a very common presentation in otorhinolaryngology clinics. It has diverse aetiology and varied symptoms at presentation. Its treatment requires a comprehensive approach for successful outcomes. We in the present study tried to evaluate the aetiology of chronic maxillary sinusitis and outcomes of treatment of chronic maxillary sinusitis.
\end{abstract}

Methods: Patients presenting with clinical features of Chronic rhinosinusitis of all age groups and sexes were included in the study. The patients were subjected to general examination from head to toe which included the examination of the Respiratory system and cardiovascular system. ENT examination along with head neck was done. X-Ray (Water's view), C.T Scan PNSCoronal, and Sagittal sections for selected patients.

Results: Antibiotics, antihistamines, decongestants, steam inhalations, and in some cases intranasal steroids (Budesonide, Beclomethasone, Fluticasone). Surgery: Antral wash $n=16$ cases, Intranasal Antrostomy $n=2$ cases, Caldwell Luc $n=2$ cases, Maxillary sinoscope $n=2$ cases, FESS $n=38$ cases involvinguncinectomy, middle meatal antrostomy, anterior ethmoidectomy, posterior ethmoidectomy, sphenoidotomy, frontal sinus infundibulotomy, and polypectomy.

Conclusion: The commonest organism responsible was streptococcus pneumoniae. Improvement in the diagnostic techniques and availability of nasal endoscopy and CT scan which can show clearly the anatomy of osteomeatal complex has led to better management of the disease. Nasal endoscopes have allowed a meticulous delicate removal of the diseased mucosa which preserving the normal mucosa and structures consequently the postoperative complications are very few and most of the cases get relief from the symptoms of the disease.
Keywords: chronic maxillary sinusitis, Antral wash, Functional Endoscopic sinus surgeries

\section{INTRODUCTION}

The terms 'Rhinosinusitis' refers to a group of disorders characterized by inflammation of the mucosa of the nose and paranasal sinuses.Chronic rhinosinusitis is diagnosed when the duration of symptoms lasts greater than 12 weeks. [1]Chronic maxillary sinusitis is the most common form of sinusitis. It is an extremely prevalent disorder that has a significant impact on the quality of life of an affected individual.The causes can be anatomical, physiological, or pathological which ultimately obstructs the free drainage from sinuses causes stasis, and predisposes to infections. Maxillary sinuses are fully dependent on the patency of the anterior ethmoidal region because their ventilation and drainage pass through complicated fissures and narrow compartments. [2] It has been estimated that 24 million people are affected by sinusitis annually. [3]The prevalence of sinusitis (146/1000) has been reported to exceed that of any other chronic condition and is apparently on the rise. It is estimated that between 30 and $50 \%$ of all patients seen by the family practitioner suffer from some form of rhinosinusitis. [4] In the USA $20 \%$ of outpatient antibiotic prescriptions are due to acute or chronic sinusitis. [5]Symptoms of chronic sinusitis are non-specific and may be misleading they are attributed to sinonasal inflammation which is marked by nasal congestion, nasal stuffiness, nasal airway obstruction, and decreased sense of smell and taste. Facial pressure or facial pain may be present along with fatigue malaise, ear pressure, and maxillary dental pain or headache. Based on the clinical examination the cases are sometimes divided into cases with polyps and cases without polyps. The presence of polyps is known as chronic hyperplastic sinusitis causes of it can be ranging from allergy, dusts pollen,environmental factors, bacterial infections. Non allergic factors such as vasomotor rhinitis can also cause chronic sinus 
problems. [6] Infection of adenoids and tonsils may spread into the sinuses.With the increase in the incidence of HIV/AIDS, Diabetes, and various other immune suppressor diseases, the incidence of bacterial especially fungal rhinosinusitis is becoming a challenging problem for an ENT Surgeon. Dental infections or extraction of the tooth may cause infection of maxillary antrum from dental canal root. Swimming and diving may cause the direct spread of materials from the nose through the ostium into paranasal sinuses. Fractures involving sinuses may be followed by sinusitis by either direct spread through the fracture site or infections of a blood clot. With the advent of endoscopic anatomy and pathophysiology of the nose and paranasal sinuses, the treatment of sinus disease assured excellent results with less recurrence. There are various modalities of treatment based on the diagnosis of etiological factors treated with medical management or surgical management. The various surgical forms of treatment have been divided for this condition such as Antral wash, Intranasal antrostomy, Caldwell- Luc, FESS. We in the present study tried to evaluate the various modalities of treatment and outcomes in patients with chronic maxillary sinusitis.

\section{Material and Methods}

This cross-sectional study was conducted in the Department of Otorhinolaryngologyof Prathima Institute of Medical Sciences, Karimnagar, Telangana State. Institutional ethical committee permission was obtained for the study after following the protocol for human studies. Written consent was obtained from all the participants of the study after explaining the nature of the study. Sample size calculation was done with formula $4 \mathrm{pq} / \mathrm{d} 2$, the following values were used. Confidence Interval $90 \%$, Margin of Error $8 \%$, the proportion of the population affected by the disease is approximately $15 \%$ the calculated sample size was 55 we included $n=60$ cases in our study.

\section{Inclusion Criteria}

1. Patients presenting with clinical features of chronic rhinosinusitis of all age groups and sexes.

2. Those who were voluntarily willing to participate in the study.

3. Those who were available for follow-up examinations.

\section{Exclusion criteria}

1. All patients presenting with clinical features other than sinusitis.

2. All cases of chronic rhinosinusitis involving other than maxillary sinus.
3. Previous cases of chronic rhinosinusitis with postoperative complications.

4. Patients presenting with acute sinusitis.

After the selection of the patient a complete history of present illness including the history, and the family history was noted, and the demographic profile of the patient was recorded. The patient was subjected to general examination from head to toe which included the examination of the Respiratory system and cardiovascular system. ENT examination along with head neck was done.

Investigations: All the $n=60$ patients were subjected to clinical examination andinvestigated by the following methods.

Haematological: Baseline hematological investigations like $\mathrm{Hb} \%$, total WBC counts, differential count, E.S.R, bleeding time, clotting time, platelet count,R.B.S/F.B.S, blood urea, A.E.C, HBsAg, HIV were done for all patients. Radiological: X-Ray (Water's view), C.T Scan PNS-Coronal, and Sagittal sections for selected patients.Diagnostic Nasal EndoscopyHistopathology: H.P.E of tissue obtained during surgery.Microbiology: Culture and sensitivity for bacteria and fungus.

Management: Antibiotics, antihistamines, decongestants, steam inhalations, and insome cases intranasal steroids (Budesonide, Beclomethasone, Fluticasone).Surgery: Antral wash $n=16$, Intranasal Antrostomy $n=2$, Caldwell Luc $n=2$, Maxillary sinoscope $n=2$, FESS $n=38$ involvinguncinectomy, middle meatal antrostomy, anterior ethmoidectomy, posterior ethmoidectomy, sphenoidotomy, frontal sinus infundibulotomy, and polypectomy.

Postoperative: Antibiotics for 7-10 days, antihistamines for 1015 days, nasaldouching, steam inhalations, intranasal steroids (Budesonide, Fluticasone) for 1-2months. Postoperati vesystemic steroids (Prednisolone - tapering dose for 10-15days in some cases). Follow-up:Patients were followed twice weekly for the first 2 weeks, once a week forthe next 2 weeks, once a month for 6 months. At each visit, the examination was done.

\section{Results}

Out of the $n=60$ cases $n=33(55 \%)$ were male patients and $n=27(45 \%)$ were female patients. The youngest case in the study was 15 years and the oldest was 59 years. Most of the cases in both males and females were from the age group $21-$ 30 years indicating that this group is most affected by the disease given in table 1.

Table 1: Demographic profile of the cases included in the study

\begin{tabular}{|c|c|c|c|c|}
\hline Age group & Male $(\mathrm{n})$ & Female $(\mathrm{n})$ & Total $(\mathrm{n})$ & Percentage \\
\hline $15-20$ & 04 & 01 & 05 & 08.33 \\
\hline $21-30$ & 15 & 16 & 31 & 51.67 \\
\hline $31-40$ & 06 & 05 & 11 & 18.34 \\
\hline
\end{tabular}




\begin{tabular}{|c|c|c|c|c|}
\hline $41-50$ & 05 & 03 & 08 & 13.33 \\
\hline $51-60$ & 03 & 02 & 05 & 08.33 \\
\hline Total & 33 & 27 & 60 & 100 \\
\hline
\end{tabular}

The common cause of seeking medical care was symptoms of headache, nasal obstruction and nasal discharge is greater than $90 \%$ of cases and $61.67 \%$ also reported with pharyngeal infections. In this study, the duration of symptoms

\begin{tabular}{|c|c|c|}
\hline Symptoms & Frequency (n) & 91.67 \\
\hline Nasal discharge & 55 & 93.33 \\
\hline Nasal obstruction & 56 & 75.00 \\
\hline Post-nasal discharge & 45 & 28.33 \\
\hline Epistaxis & 17 & 25.00 \\
\hline Hyposmia/anosmia & 15 & 61.67 \\
\hline Pharyngeal infections & 37 & 96.67 \\
\hline Headache & 58 & 03.30 \\
\hline Orbital symptoms & 02 & 08.30 \\
\hline Respiratory tract infections & 05 & 10.00 \\
\hline sneezing & 06 & 05.00 \\
\hline Dental problems & 03 & 05.00 \\
\hline Mouth breathing/snoring & 03 & \\
\hline
\end{tabular}

After the ENT examination of the selected cases, half of the cases had deviated nasal septum which was the cause

of chronic sinusitis. There was hypertrophy of inferior turbinate in $46 \%$ of cases and other abnormalities were found ranging from $3 \%-5 \%$ in the cases as shown in table 3.

Table 3: Signs recorded in the cases included in the study

\begin{tabular}{|c|c|c|}
\hline Signs & Frequency (n) & Percentage (\%) \\
\hline Deviated Nasal septum & 31 & 46.67 \\
\hline Hypertrophy inferior turbinate & 28 & 05.00 \\
\hline Bilateral polyps & 03 & 03.33 \\
\hline Unilateral polyps & 02 & 08.33 \\
\hline Antrochoanal polyp & 05 & 05.00 \\
\hline Pan Sinusitis & 03 & 06.67 \\
\hline Dental origin & 04 & 03 \\
\hline Adenoid hypertrophy & 05.00 \\
\hline
\end{tabular}




\begin{tabular}{|c|c|c|} 
ISSN (P) 2348-1447 ISSN (0) 2338-229X & Percentage (\%) \\
\hline Bacteria & Frequency (n) & 03.33 \\
\hline Staphylococcus aureus & 02 & 01.67 \\
\hline Streptococcus pyogenes & 01 & 28.33 \\
\hline Streptococcus pneumonia & 17 & 25.00 \\
\hline Hemophilus influenza & 15 & 11.67 \\
\hline Moraxella catarrhalis & 07 & 01.67 \\
\hline Pepto streptococcus & 01 & 01.67 \\
\hline Fuso bacteria & 01 & 01.67 \\
\hline Fungal aspergillus & 01 & 25.00 \\
\hline No growth & 15 & . \\
\hline
\end{tabular}

Figure 1: Showing the surgical procedures undertaken

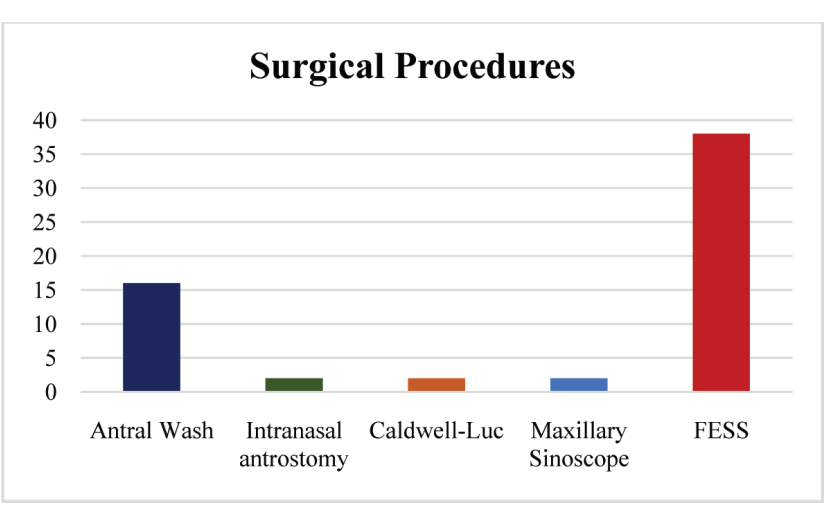

In $n=38$ cases Functional Endoscopic sinus surgeries were done antral wash was done in $n=16$ cases, intranasal antrosomy in $\mathrm{n}=2$ cases, Caldwell Luc operation in $\mathrm{n}=2$ cases, maxillary sinscope surgery in $n=2$ cases given in figure 1 . Uncinectomy in $n=10$ cases, middle meatal antrostomy in $n=7$ cases, anterior meatal antrostomy in $n=6$ cases, posterior meatal antrosomy in $n=5$ cases, sphenoidotomy in $n=3$ cases frontal sinus surgery in $n=1$ case, and polypectomy in $n=6$ cases given in figure 2 .

Table 2: Functional Endoscopic sinus surgery procedures

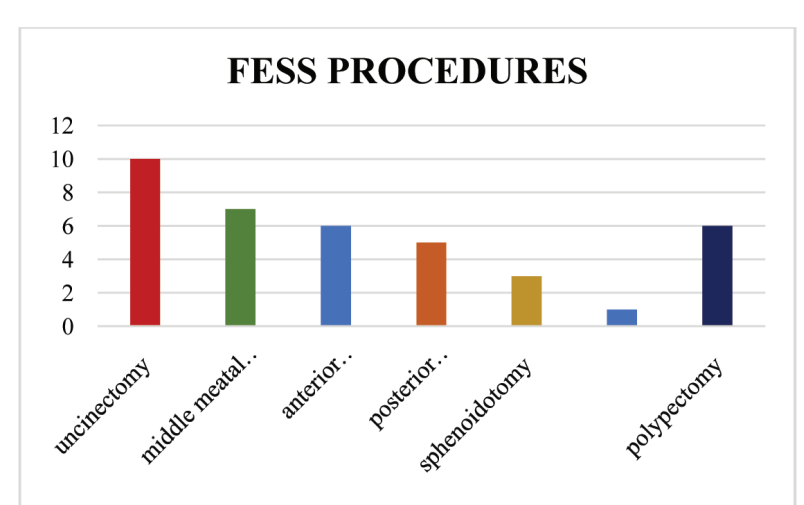

Postoperative complications distribution: No major postoperative complications were noted in the postoperative period. The minor postoperative complications include synechiae formation which was noted in $n=3$ patients $(5 \%)$ who have undergone FESS at the end of the 2 nd week and the incidence dropped to $0 \%$ by the end of the 12 th week.

\section{Discussion}

Rhinosinusitis presents with variable clinical features in patients depending upon the actual pathogenesis underlying the disease. The present study is an attempt to determine the clinical features, application of required diagnostic criteria used by various authors, correlate the radiological features with the clinical signs, and per-operative findings. Nasal smears, Nasal swabs, and tissue collected during the surgery were subjected to laboratory study to arrive at the diagnosis. An attempt was also made to study the role of various treatment modalities used during the management of the disease. Out of the $n=60$ cases, the youngest case in the study was 15 years and the oldest was 59 years commonly affected age group was $21-30$ years.According to McNeil RA et al; ${ }^{[7]}$ the maximum age incidence was inthe 4 thdecade. While in the studies by

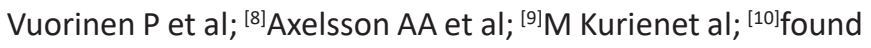
the highest incidence in the 20-29 age group (3rddecade)agreeing with the observations of the present study.In this study, we found $55 \%$ were male patients and $45 \%$ were female patients. In the current study symptoms of headache $96.67 \%$, nasal obstruction in $93.33 \%$, and nasal discharge in $91.67 \%$ of cases.In SR Nayak et al; ${ }^{[11]}$ study the commonest symptom was nasal discharge followed by headache and nasal obstruction. Nasal obstruction was the commonest symptom (96\%) followed by postnasal drip (92\%) \& facial pain/headache $(90 \%)$ in the study byMathews BL et 
al; ${ }^{[12]}$ and Fageeh NA et al; ${ }^{[13]}$ study the commonest complaint was nasal obstruction (76\%), headache $(74.4 \%)$, anosmia (56.5\%) \& facial pressure/pain (50\%).In our study deviated nasal septum was seen in $51.67 \%$ of cases. Maru YK et al; ${ }^{[14]}$ found deviated nasal septum in $55.7 \%$ of cases and Asruddin et $\mathrm{al}^{[15]}$ found in $38 \%$ of cases. Jareoncharsri $\mathrm{P}$ et al; ${ }^{[16]}$ septal deviation is obvious in $60(72.3 \%)$ of the patients out of 83 cases on DNE. In the current study, we found the commonest organism isolated from the secretions to be Streptococcus pneumoniae(28.33\%). Brook I et al; ${ }^{[17]}$ identified chronic rhinosinusitis in the aspirations of sinus secretions by endoscope from 80 patients in their study, demonstrating the Streptococcus pneumoniae is the commonest bacterial cause.Gwaltney JMet al; ${ }^{[18]}$ found Streptococcus pneumoniae (20-45\%)and Haemophilus influenzae (22-35\%) are the predominant organisms in acutebacterial rhinosinusitis in adults. In the present study, all patients received Preoperative Antibiotics, Antihistamines, decongestants, steam inhalations, and in some patients transnasal steroids (Budesonide, Beclomethasone, Fluticasone). In this study, $n=38$ cases underwent FESS surgery and postoperatively $n=30$ (78.95\%) cases have significant improvement and relief from symptoms of chronic sinusitis. Behin $\mathrm{F}$ et a; ${ }^{[19]}$ patients underwent FESS surgery $83 \%$ of patients no longer complained of headache and $8 \%$ had significant relief. A study conducted by Parsons DS et al; ${ }^{[21]}$ on 34 patients who underwent FESS surgery reported a reduction in intensity in $91 \%$ of patients and a reduction in the frequency of headache in $85 \%$ of patientsposto peratively.No major postoperative complications were noted in the postoperative period. Theminor postoperative complications include synechiae formationwhich was noted in $n=3$ patients (5\%) who have undergone FESS at the end of the 2 nd week and the incidence dropped to $0 \%$ by the end of the 12th week. A study by K J Jacob et al; ${ }^{[21]}$ found Synechiae formation between the middle turbinate at the end of 2 weeks and long-term follow-up showed normal endoscopic findings.

\section{Conclusion}

Under the limitations of the current study, it was found chronic maxillary sinusitis affects all age groups and however predominantly found in the 3rd decade. The commonest organism responsible was streptococcus pneumoniae. Improvement in the diagnostic techniques and availability of nasal endoscopy and CT scan which can show clearly the anatomy of osteomeatal complex has led to better management of the disease. Nasal endoscopes have allowed a meticulous delicate removal of the diseased mucosa which preserving the normal mucosa and structures consequently the postoperative complications are very few and most of the cases get relief from the symptoms of the disease.

\section{REFERENCES}

1. WW Stevens, RP Schleimer, RC Kern. Chronic Rhinosinusitis with Nasal Polyps. J Allergy Clin Immunol Pract. 2016; 4(4):565-72.

2. Kamel RH. Nasal endoscopy in chronic maxillary sinusitis. The J Laryngol Otol. 1989;103:275-78.

3. Rosenfeld RM, Andes D, Bhattacharyya N, et al. Clinical practice guideline: adult sinusitis. Otolaryngol Head Neck Surg 2007; 137:1-31.

4. AD Havale, AY Rajguru. A prospective study of bacteriology and antibiotics treatment of maxillary sinusitis. International Journal of Medical and Health Research 2018; 4(5):142-44.

5. Marple BF, Brunton S, Ferguson BJ. Acute bacterial rhinosinusitis: a review of US treatment guidelines. Otolaryngol Head Neck Surg 2006; 135:341-48.

6. Fauci SA, Kasper DL, Braunwald E, Hauser SL, et al. Harrison's Principles of Internal Medicine. 17th ed, Vol 1. Chicago, U.S: R.R Donnelley and Sons Inc 1999;511.

7. McNeil RA. Comparison of findings on transillumination, $\mathrm{X}$-ray, andlavage of the maxillary sinus. J Laryngol Otol. 1963; 77: 1009- 13.

8. Vuorinen P, Kauppila A, Pulkkinen K. Comparison of results of roentgenexamination and antral puncture and irrigation.J LaryngolOtol.1962;76:359-64.

9. Axelsson AA, Grebelius N, Chidekel N, Jensen C. The correlation between the radiologicalexamination and the irrigation findings in maxillary sinusitis. Acta Otolaryngol1970; 69: 302-06.

10. M Kurien, R Raman, A. Job. Roentgen Examination of Maxillary Sinus, AntralPuncture and Irrigation - A Comparative study. Sing Med J1989;30:565-67.

11. Nayak SR,Kirtane MV,Ingle MV.Functional endoscopic sinus surgery:Anatomy, diagnosis evaluation, and technique. J Postgrad Med1991;37: 26-30.

12. Mathews BL, Smith LE, Jones $R$, Miller $C$, and Brookschimdt JK.Endoscopicsinus surgery- outcome in 155 cases. Otolaryngol Head Neck Surg1991; 104(2): 24446.

13. Fageeh NA, Peluausa EO, Quarrington A. Functional endoscopic sinussurgery- University of Ottawa experience and an overview. Ann Saudi Med 1996; 16(6): 711-14.

14. Maru YK, Gupta V. Anatomical variations of the bone in sinonasal CT. IndianJ Otolaryngol and Head and Neck Surg 2001;53:123-128. 
15. Asruddin, Yadav SPS, Yadav RK, Singh J. Lowdose Clin chronic sinusitis. Indian J Otolaryngol and Head and Neck Surg 2000;52:17-21.

16. Jareoncharsri $P$, Thitadilok $V$, Bunnag $C$, et al. Nasal endoscopic findings in patients with perennial allergic rhinitis. Asian Pac J Allergy Immunol. 1999;17(4):261-67.

17. Brook I, Yocum P, Frazier EH. Bacteriology and betalactamase activity inacute and chronic maxillary sinusitis. Arch Otolaryngol Head Neck surgery1996; 122:418-22.

18. Gwaltney JM Jr, Scheld WM, Sande MA, Sydnor A. The microbial etiology and antimicrobial therapy of adults with acute community-acquiredsinusitis: a fifteen-year experience at the University of Virginia andreview of other selected studies. J Allergy Clin Immunol 1992; 90:457-62.

19. Behen $\mathrm{F}$ et al. Surgical management of contact point headache. Headache2005; 45(3): 204-10.

20. Parsons DS, Batra PS. FESS outcomes for contact point headache. Laryngoscope 1998; 108(5): 696-02.

21. K J Jacob, S Geroge, S Preethi, VS Arunraj. A comparative study between endoscopic middle meatal antrostomy and Caldwell-Luc surgery in the treatment of chronic maxillary sinusitis. Indian J Otolaryngol Head Neck Surg 2011;63(3):214-19.

How to cite this article : Sakinala S. A Clinical Study of Different Modalities for the Management of Chronic Maxillary Sinusitis. Perspectives in Medical Research 2021; 9 (1):28-33 DOI:10.47799/pimr.0901.23

Sources of Support: Nil, Conflict of interest: None declared 